\title{
Intravitreal Corticosteroids in the Management of Diabetic Macular Edema
}

\author{
Stephen G. Schwartz • Harry W. Flynn Jr. • \\ Ingrid U. Scott
}

Published online: 26 July 2013

(c) Springer Science + Business Media New York 2013

\begin{abstract}
Diabetic macular edema (DME) remains an important cause of visual loss worldwide. Corticosteroids have a role in the treatment of some patients with advanced or recurrent DME. The best studied steroids for this indication are triamcinolone acetonide, dexamethasone, and fluocinolone acetonide. All steroids are associated with risks of cataract and intraocular pressure elevation. In addition, intravitreal injection of any medication is associated with such risks as infectious endophthalmitis, which has led to the investigation of various extended-release steroid implants. At this time, no steroid is approved by the United States Food and Drug Administration for the treatment of DME.
\end{abstract}

Keywords Diabetic macular edema .

Triamcinolone acetonide · Fluocinolone acetonide .

Dexamethasone $\cdot$ Randomized clinical trial

S. G. Schwartz $(\bowtie)$

Department of Ophthalmology, Bascom Palmer Eye Institute, University of Miami Miller School of Medicine,

311 9th Street North, \#100, Naples,

FL 34102, USA

e-mail: sschwartz2@med.miami.edu

H. W. Flynn Jr.

Department of Ophthalmology, Bascom Palmer Eye Institute, University of Miami Miller School of Medicine,

900 NW 17th Street, Miami, FL 33136, USA

e-mail: hflynn@med.miami.edu

\section{U. Scott}

Departments of Ophthalmology and Public Health Sciences, Penn State College of Medicine, 500 University Drive, HU19, Hershey, PA 17033, USA

e-mail: iscott@hmc.psu.edu

\section{Introduction}

Diabetic macular edema (DME) remains an important cause of visual loss worldwide. Diabetic retinopathy is thought to occur through a number of metabolic pathways, including the formation of reactive oxygen species, the formation of advanced glycation endproducts, the accumulation of polyol through the action of the enzyme aldose reductase, and activation of protein kinase $\mathrm{C}$ via expression of vascular endothelial growth factor (VEGF) [1].

Tighter control of systemic factors, such as hypertension, hyperglycemia, and hyperlipidemia, is generally beneficial in reducing retinopathy in patients with both type 1 [2] and type 2 [3] diabetes mellitus. Focal/grid photocoagulation has demonstrated efficacy in a large, prospective, randomized clinical trial (RCT) [4]. Nevertheless, many patients continue to lose vision despite these interventions [5], which has led to the investigation of pharmacologic therapies for DME [6]. The two major categories of medications currently used to treat DME are anti-VEGF agents and corticosteroids.

The two most commonly used anti-VEGF agents are bevacizumab and ranibizumab. Bevacizumab (Avastin, Genentech, South San Francisco, CA), a recombinant humanized full-length antibody against all isoforms of VEGF-A, is FDA-approved for the systemic treatment of metastatic colorectal and other cancers [7]. Off-label intravitreal bevacizumab has been reported to have shortterm efficacy in the treatment of DME in multiple RCTs [8, 9]. Ranibizumab (Lucentis, Genentech, South San Francisco, CA), a recombinant humanized antibody fragment against all isoforms of VEGF-A, is FDA-approved for the intravitreal treatment of exudative age-related macular degeneration $[10,11]$ and macular edema secondary to retinal vein occlusion at a $0.5 \mathrm{mg}$ dose $[12,13]$. Ranibizumab 
at a $0.3 \mathrm{mg}$ dose was FDA-approved for the treatment of DME $[14,15]$.

The mechanism of action of corticosteroids in the treatment of DME is thought to be multifactorial [16]. Corticosteroids are powerful non-specific anti-inflammatory agents and have also been reported to antagonize the action of VEGF [17, 18]. Data available to date suggest that corticosteroids are most effective against DME when delivered intravitreally. The Diabetic Retinopathy Clinical Research (DRCR) network conducted a RCT and reported that peribulbar triamcinolone acetonide was not associated with significant benefits in patients with mild DME [19].

Three potent synthetic corticosteroids with similar chemical structures have been investigated as intravitreal treatments for DME: triamcinolone acetonide, dexamethasone, and fluocinolone acetonide [20]. In general, intravitreal medications are cleared relatively rapidly from the eye [21]. Triamcinolone acetonide, dexamethasone, and fluocinolone acetonide all have been reported to have an elimination half-life in the vitreous of 2-3 hours in animal models [20]. In order to increase the duration of action, the medication may be dissolved slowly from a crystal structure (e.g., triamcinolone acetonide) or a specific slowrelease device may be utilized (e.g., dexamethasone, fluocinolone acetonide) [20].

Intravitreal triamcinolone acetonide, a suspension, is typically effective for about three months in a non-vitrectomized eye [22], so repeated injections may be necessary to maintain the treatment effect. Intravitreal injections are associated with approximately a $0.05 \%$ risk of infectious endophthalmitis per injection [23]. Intravitreal corticosteroids are also associated with additional risks of cataract onset/progression [24], pseudo-endophthalmitis [25], and elevated intraocular pressure (IOP) [26].

In order to mitigate the cumulative risks associated with repeated intravitreal injections, extended-release steroid implants have been investigated for the treatment of DME. In addition, it has been suggested that extended delivery of lower doses of steroids may be more effective than intermittent bolus delivery of high doses [27]. In general, non-bioerodable implants are associated with more precise control of drug release than are bioerodable implants [21].

\section{Triamcinolone Acetonide}

At least four different preparations of triamcinolone acetonide have been used in various clinical trials: Kenalog-40 (Bristol-Myers Squibb, Princeton, NJ) [28], Triesence
Fig. 1 a A 74-year-old woman with type 2 diabetes mellitus presented with bilateral recurrent diabetic macular edema (DME) following photocoagulation. Visual acuity was 20/80 OD and 20/200 OS. An optical coherence tomography (OCT) slice OD demonstrates cystoid macular edema (CME) and subretinal fluid. b An OCT map OD demonstrates macular thickening. c An OCT slice OS demonstrates CME and subretinal fluid. d An OCT map OS demonstrates macular thickening. e The patient was treated with intravitreal triamcinolone acetonide, $4 \mathrm{mg}$ in $0.1 \mathrm{cc}$, OU. Two months later, visual acuity improved to 20/40 OD and 20/60 OS. An OCT slice OD demonstrates improvement in CME and subretinal fluid. f An OCT map OD demonstrates improvement in macular thickening. g An OCT slice OS demonstrates improvement in CME and subretinal fluid. h An OCT map OS demonstrates improvement in macular thickening

(Alcon, Ft. Worth, TX) [29], Trivaris (Allergan, Irvine, CA) [30], and preservative-free triamcinolone acetonide obtained from compounding pharmacies [31]. In a large RCT, the DRCR network compared two doses (1 and $4 \mathrm{mg}$ ) of intravitreal triamcinolone acetonide with photocoagulation in the treatment of DME. The DRCR reported that photocoagulation was associated with generally more favorable anatomic and visual outcomes at two years [32] and three years [33•] follow-up. Nevertheless, triamcinolone may be effective for selected patients, especially those with poor presenting visual acuity and those with persistent or recurrent DME (Fig. 1) [34].

More recently, combination therapy with photocoagulation and/or anti-VEGF drugs has been investigated. In a $\mathrm{RCT}$, the DRCR randomized patients with DME to receive prompt focal/grid photocoagulation, ranibizumab plus prompt photocoagulation, ranibizumab plus deferred photocoagulation, or triamcinolone acetonide plus prompt photocoagulation. The DRCR reported that, compared with photocoagulation, ranibizumab plus photocoagulation (prompt or deferred) was associated with significantly improved visual outcomes at one year. Triamcinolone acetonide plus photocoagulation was associated with generally more favorable outcomes than was photocoagulation in pseudophakic eyes only [35]. The DRCR subsequently reported 2-year outcomes from this same RCT that were similar to the 1-year outcomes [36•]. In a separate RCT, the DRCR reported that adding either ranibizumab or triamcinolone acetonide to focal/grid photocoagulation was associated with improved outcomes in eyes also receiving panretinal photocoagulation [37].

In a RCT from Iran, focal/grid photocoagulation, bevacizumab, and bevacizumab plus triamcinolone acetonide were associated with similar visual outcomes at two years [38]. In a RCT from Korea, bevacizumab, triamcinolone acetonide, and combined bevacizumab plus triamcinolone acetonide were associated with similar outcomes at 

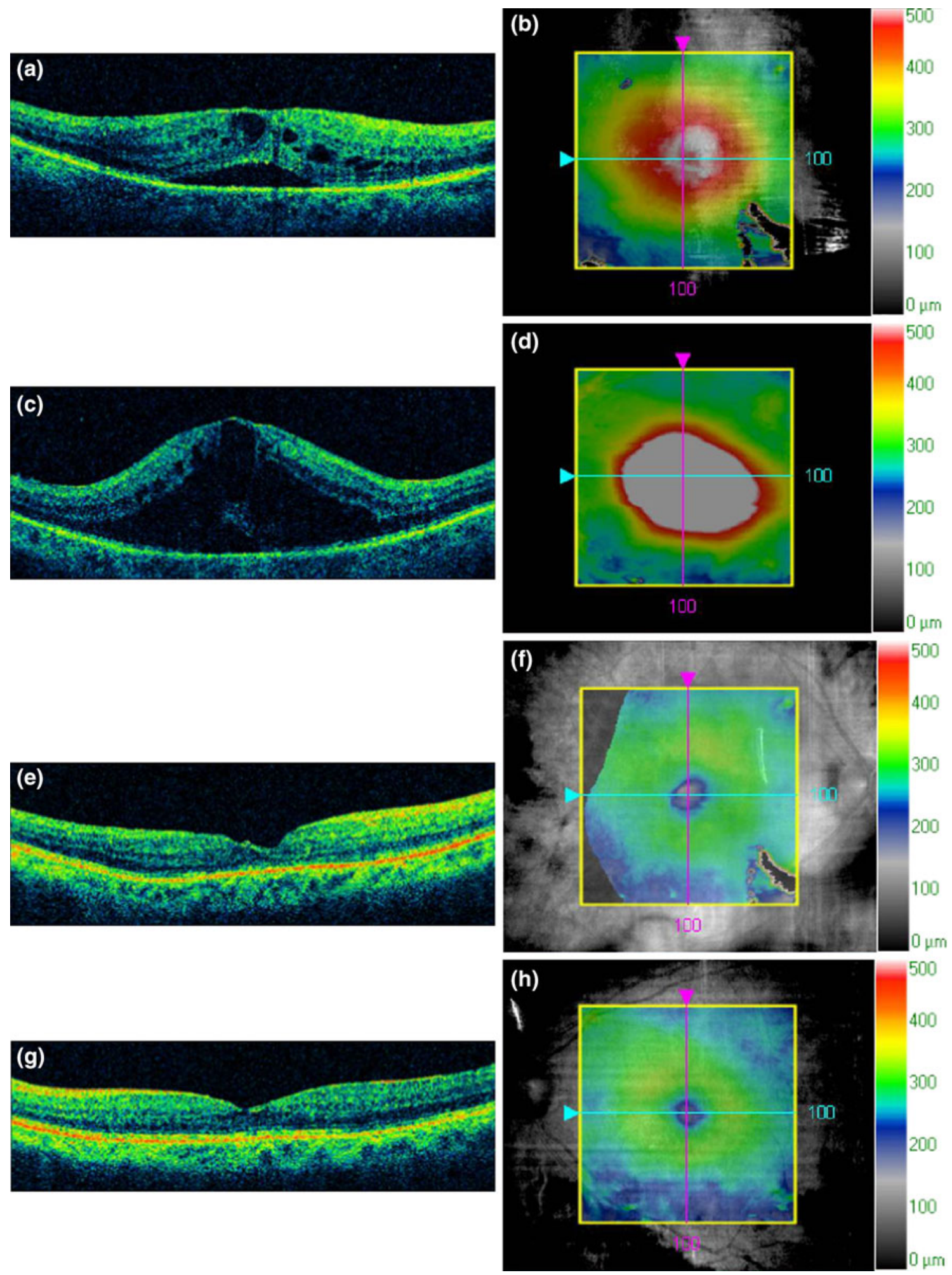

one year [39]. In a RCT from Australia, triamcinolone acetonide plus focal/grid photocoagulation was associated with better visual outcomes than was photocoagulation alone, but risks of cataract and IOP elevation were reported [40].

\section{Dexamethasone}

In a pilot study of 12 patients followed for three months, a single injection of intravitreal dexamethasone ( 0.4 or $0.8 \mathrm{mg}$ ) was not beneficial in the treatment of DME [41]. 
This was a small study with a short follow-up period, and a more definitive RCT would be necessary to draw any further conclusions.

A bioerodable, extended-release dexamethasone implant (Ozurdex, Allergan, Irvine, CA), which is injected in the clinic, has received US FDA approval for the treatment of macular edema associated with retinal vein occlusion [42] and noninfectious posterior segment uveitis [43]. The device contains $700 \mu \mathrm{g}$ of dexamethasone in a solid, bioerodable polymer. In a monkey model, peak concentrations of dexamethasone were detected in the vitreous and retina for the first two months, followed by a gradual decrease to below the limits of quantitation by six months [44].

In a phase II RCT, a 700- $\mu \mathrm{g}$ dexamethasone implant was associated with significantly improved anatomic and visual outcomes in patients with persistent DME, defined by the study investigators as DME persisting for at least 90 days following photocoagulation or medical therapy [45•]. In a subsequent analysis of these data, the study investigators reported similar efficacy of the dexamethasone implant in patients with multiple patterns of DME [46]. In a small, open-label clinical trial, a single dexamethasone implant was associated with improved outcomes in vitrectomized eyes with DME at 26 weeks follow-up [47].

\section{Fluocinolone Acetonide}

A non-bioerodable, extended-release fluocinolone acetonide implantable device (Retisert, Bausch + Lomb, Rochester, NY), which must be sutured to the sclera in an operating room, has received US FDA approval for the treatment of noninfectious posterior segment uveitis [48]. The device contains $0.59 \mathrm{mg}$ of fluocinolone acetonide coated with polyvinyl alcohol and releases approximately $0.5 \mu \mathrm{g}$ per day for approximately three years [21]. In two phase III RCTs, the device was associated with improved visual and anatomic outcomes in eyes with DME, but also with high rates of cataract progression and IOP elevation [49, 50]. In a more recent evaluator-masked clinical trial, the device was associated with improved outcomes in eyes with persistent or recurrent DME (defined by the study investigators as DME status-post at least one focal/grid photocoagulation at least 12 weeks prior to study entry) at three years [51•].

A much smaller, non-bioerodable, extended-release fluocinolone acetonide injectable device (Iluvien, Alimera, Alpharetta, GA), which is injected in a clinic setting, has been investigated for the treatment of DME [52]. The pharmacokinetic and efficacy study of fluocinolone acetonide inserts in patients with DME (FAMOUS) study was a phase II RCT that randomized 37 patients to receive either a $0.2-$ or $0.5-\mu \mathrm{g} /$ day device. The group reported sustained intraocular release of medication in both groups at one year
[27]. The Fluocinolone Acetonide for Macular Edema (FAME) studies were two phase III RCTs that collectively randomized 956 patients with persistent DME following photocoagulation to receive a $0.2-\mu \mathrm{g} /$ day implant, a $0.5-\mu \mathrm{g} /$ day implant, or a sham injection. The primary end point was improvement in best-corrected visual acuity of at least 15 letters at 24 months. In both treatment groups, approximately $28 \%$ of patients achieved this end point, as opposed to approximately $16 \%$ of sham-treated patients. Subsequent cataract surgery was reported in $41 \%$ of patients receiving a $0.2-\mu \mathrm{g} / \mathrm{day}$ implant, $51 \%$ of patients receiving a $0.5-\mu \mathrm{g} / \mathrm{day}$ implant, and only $7 \%$ of patients receiving the sham injection. Increased IOP requiring incisional glaucoma surgery was reported in $3.7 \%$ of patients receiving a $0.2-\mu \mathrm{g} /$ day implant, $8.1 \%$ of patients receiving a $0.5-\mu \mathrm{g} /$ day implant, and only $0.5 \%$ of patients receiving a sham injection [53].

In late 2011, the US FDA announced that it would not approve the Iluvien device for DME. Subsequently, the device has achieved approval in several European nations and the pharmaceutical company has re-applied for US FDA approval.

\section{Conclusion}

At this time, no steroid has achieved US FDA approval for the treatment of DME. Nevertheless, steroids do have a role in the treatment of certain patients with persistent or recurrent disease, especially pseudophakes. The Iluvien implant is not FDA-approved in the US and is only available through a clinical trial. The other extended-release devices (Ozurdex and Retisert) are FDA-approved for diagnoses other than DME, and are not frequently used in an off-label capacity because of their high costs. Therefore, in the US, the various preparations of triamcinolone acetonide are used most frequently as off-label treatments for DME. As data from RCTs continue to accumulate, a better understanding of the role of pharmacologic therapy for DME will be reached.

Acknowledgments This study was partially supported by $\mathrm{NIH}$ Center Core Grant P30EY014801, an Unrestricted Grant from Research to Prevent Blindness (New York, NY), and the Department of Defense (DOD Grant \#W81XWH-09-1-0675).

Disclosure Stephen G. Schwartz has performed consulting activities for Alimera and Bausch + Lomb, has received lecture fees from Regeneron, and has received royalties from IC Labs related to the use of genetics to detect steroid responders. Harry W. Flynn has performed consulting activities for Santen and has received lecture fees from Vindico. Ingrid U. Scott has performed consulting activities for ThromboGenics and has received lecture fees from Genentech.

Human and Animal Rights and Informed Consent This article does not contain any studies with human or animal subjects performed by any of the authors. 


\section{References}

Papers of particular interest, published recently, have been highlighted as:

- Of importance

1. Fong DS, Aiello LP, Ferris FL 3rd, Klein R. Diabetic retinopathy. Diabetes Care. 2004;27:2540-53.

2. Diabetes Control and Complications Trial Research Group: The effect of intensive treatment of diabetes on the development and progression of long-term complications in insulin-dependent diabetes mellitus. N Engl J Med. 1993;329:977-986.

3. UK Prospective Diabetes Study Group: Intensive blood-glucose control with sulphonylureas or insulin compared with conventional treatment and risk of complications in patients with type 2 diabetes: UKPDS 33. Lancet. 1998;352:837-53.

4. Early Treatment Diabetic Retinopathy Study Research Group: Photocoagulation for diabetic macular edema: Early Treatment Diabetic Retinopathy Study report number 1. Arch Ophthalmol. 1985;103:1796-1806.

5. Lee C, Olk R. Modified grid laser photocoagulation for diffuse diabetic macular edema: long-term visual results. Ophthalmology. 1991;98:1594-602.

6. Javey G, Schwartz SG, Flynn HW Jr.: Emerging pharmacotherapies for diabetic macular edema. Exp Diabetes Res. 2012;2012:548732.

7. Yang JC, Haworth L, Sherry RM, et al. A randomized trial of bevacizumab, an anti-vascular endothelial growth factor antibody, for metastatic renal cancer. N Engl J Med. 2003;349:427-34.

8. Diabetic Retinopathy Clinical Research Network, Scott IU, Edwards AR, et al. A phase II randomized clinical trial of intravitreal bevacizumab for diabetic macular edema. Ophthalmology. 2007;114:1860-7.

9. Michaelides M, Kaines A, Hamilton RD, et al. A prospective randomized trial of intravitreal bevacizumab or laser therapy in the management of diabetic macular edema (BOLT study): 12 month data. Report 2. Ophthalmology. 2010;117:1078-86.

10. Rosenfeld PR, Brown DM, Heier JS, et al. Ranibizumab for neovascular age-related macular degeneration. N Engl J Med. 2006;355:1419-31.

11. Brown DM, Kaiser PK, Michels M, et al. Ranibizumab versus verteporfin for neovascular age-related macular degeneration. N Engl J Med. 2006;355:1432-44.

12. Campochiaro PA, Heier JS, Feiner L, et al. Ranibiumab for macular edema following branch retinal vein occlusion: sixmonth primary end point results of a phase III study. Ophthalmology. 2010;117:1102-12.

13. Brown DM, Campochiaro PA, Singh RP, et al. Ranibizumab for macular edema following central retinal vein occlusion: sixmonth primary end point results of a phase III study. Ophthalmology. 2010;117:1124-33.

14. Massin P, Bandello F, Garweg JG, et al. Safety and efficacy of ranibizumab in diabetic macular edema (RESOLVE Study): a 12-month, randomized, controlled, double-masked, multicenter phase II study. Diabetes Care. 2010;33:2399-405.

15. Nguyen QD, Shah SM, Khwaja AA, et al. Two-year outcomes of the ranibizumab for edema of the macula in diabetes (READ-2) study. Ophthalmology. 2010;117:2146-51.

16. Golan S, Loewenstein A. Steroids and the management of macular edema. Ophthalmologica. 2010;224(Suppl 1):34-40.

17. Nauck M, Roth M, Tamm M, et al. Induction of vascular endothelial growth factor by platelet-activating growth factor and platelet-derived growth factor is downregulated by corticosteroids. Am J Respir Cell Mol Biol. 1997;16:398-406.
18. Ayalasomayajula SP, Ashton P, Kompella UB, et al. Fluocinolone inhibits VEGF expression via glucocorticoid receptor in human retinal pigment epithelial (ARPE-19) cells and TNF-alpha-induced angiogenesis in chick chorioallantoic membrane (CAM). J Ocul Pharmacol Ther. 2009;25:97-103.

19. Diabetic Retinopathy Clinical Research Network, Chew E, Strauber $S$, et al.: Randomized trial of peribulbar triamcinolone acetonide with and without focal photocoagulation for mild diabetic macular edema: a pilot study. Ophthalmology. 2007;114:1190-6.

20. Edelman JL. Differentiating intraocular glucocorticoids. Ophthalmologica. 2010;224(Suppl 1):225-30.

21. Kompella UB, Kadam RS, Lee VH. Recent advances in ophthalmic drug delivery. Ther Deliv. 2010;1:435-56.

22. Mason JO 3rd, Somaiya MD, Singh RJ. Intravitreal concentration and clearance of triamcinolone acetonide in nonvitrectomized human eyes. Retina. 2004;24:900-4.

23. Schwartz SG, Flynn HW, Scott IU. Endophthalmitis after intravitreal injections. Expert Opin Pharmacother. 2009;10:2119-26.

24. Chu YK, Chung EJ, Kwon OW, et al. Objective evaluation of cataract progression associated with a high dose intravitreal triamcinolone injection. Eye. 2008;22:895-9.

25. Moshfeghi DM, Kaiser PK, Bakri SJ, et al. Presumed sterile endophthalmitis following intravitreal triamcinolone acetonide injection. Ophthalmic Surg Lasers Imaging. 2005;36:24-9.

26. Smithen LM, Ober MD, Maranan L, Spaide RF. Intravitreal triamcinolone acetonide and intraocular pressure. Am J Ophthalmol. 2004;138:740-3.

27. Campochiaro PA, Hafiz G, Shah SM, et al. Sustained ocular delivery of fluocinolone acetonide by an intravitreal insert. Ophthalmology. 2010;117:1393-9.

28. Martidis A, Duker JS, Greenberg PB, et al. Intravitreal triamcinolone for refractory diabetic macular edema. Ophthalmology. 2002;190:920-7.

29. Dyer D, Callanan D, Bochow T, et al. Clinical evaluation of the safety and efficacy of preservative-free triamcinolone (Triesence [triamcinolone acetonide injectable suspension] $40 \mathrm{mg} / \mathrm{ml}$ ) for visualization during pars plana vitrectomy. Retina. 2009;29:38-45.

30. Ip MS, Oden NL, Scott IU, et al. SCORE Study report 3: study design and baseline characteristics. Ophthalmology. 2009;116:1770-7.

31. Bakri SJ, Shah A, Falk NS, Beer PM. Intravitreal preservativefree triamcinolone acetonide for the treatment of macular edema. Eye. 2005;19:686-8.

32. Diabetic Retinopathy Clinical Research Network: A randomized trial comparing intravitreal triamcinolone acetonide and focal/ grid photocoagulation for diabetic macular edema. Ophthalmology. 2008;115:1447-9.

33. - Beck RW, Edwards AR, Aiello LP, et al. Three-year follow-up of a randomized trial comparing focal/grid photocoagulation and intravitreal triamcinolone for diabetic macular edema. Arch Ophthalmol. 2009;127:245-51. Randomized clinical trial of triamcinolone versus photocoagulation.

34. Schwartz SG, Flynn HW Jr, Beer P. Intravitreal triamcinolone acetonide use in diabetic macular edema: illustrative cases. Ophthalmic Surg Lasers Imaging. 2010;9:1-6.

35. Diabetic Retinopathy Clinical Research Network, Elman MJ, Aiello LP, et al. Randomized trial evaluating ranibizumab plus prompt or deferred laser or triamcinolone plus prompt laser for diabetic macular edema. Ophthalmology. 2010;117:1064-77.

36. - Elman MJ, Bressler NM, Qin H, et al. Expanded 2-year followup of ranibizumab plus prompt or deferred laser or triamcinolone plus prompt laser for diabetic macular edema. Ophthalmology. 2011;118:609-14. Randomized clinical trial of ranibizumab plus photocoagulation versus triamcinolone plus photocoagulation.

37. Diabetic Retinopathy Clinical Research Network, Googe J, Brucker $\mathrm{AJ}$, et al. Randomized trial evaluating short-term effects of intravitreal ranibizumab or triamcinolone acetonide on macular edema 
after focal/grid laser for diabetic macular edema in eyes also receiving panretinal photocoagulation. Retina. 2011;31:1009-27.

38. Soheilian M, Garfami KH, Ramezani A, Yaseri M, Peyman GA. Two-year results of a randomized trial of intravitreal bevacizumab alone or combined with triamcinolone versus laser in diabetic macular edema. Retina. 2012;32:314-21.

39. Lim JW, Lee HK, Shin MC. Comparison of intravitreal bevacizumab alone or combined with triamcinolone versus triamcinolone in diabetic macular edema: a randomized clinical trial. Ophthalmologica. 2012;227:100-6.

40. Gillies MC, McAllister IL, Zhu M, et al. Intravitreal triamcinolone prior to laser treatment of diabetic macular edema: 24-month results of a randomized clinical trial. Ophthalmology. 2011;118:866-72.

41. Chan CK, Mohamed S, Lee VY, et al. Intravitreal dexamethasone for diabetic macular edema: a pilot study. Ophthalmic Surg Lasers Imaging. 2010;41:26-30.

42. Haller JA, Bandello F, Belfort R Jr. Randomized, sham-controlled trial of dexamethasone intravitreal implant in patients with macular edema due to retinal vein occlusion. Ophthalmology. 2010;117:1134-46.

43. Lowder C, Belfort R Jr, Lightman S, et al. Dexamethasone intravitreal implant for non-infectious intermediate or posterior uveitis. Arch Ophthalmol. 2011;129:545-53.

44. Chang-Lin JE, Attar M, Acheampong AA, et al. Pharmacokinetics and pharmacodynamics of a sustained-release dexamethasone intravitreal implant. Invest Ophthalmol Vis Sci. 2011;52:80-6.

45. - Haller JA, Kuppermann BD, Blumenkranz MS, et al. Randomized controlled trial of an intravitreous dexamethasone drug delivery system in patients with diabetic macular edema. Arch Ophthalmol. 2010;128:289-96. Randomized clinical trial of the dexamethasone delivery system.

46. Kuppermann $\mathrm{BD}$, Chou $\mathrm{C}$, Weinberg DV, et al. Intravitreous dexamethasone effects on different patterns of diabetic macular edema. Arch Ophthalmol. 2010;128:642-3.

47. Boyer DS, Faber D, Gupta S, et al. Dexamethasone intravitreal implant for treatment of diabetic macular edema in vitrectomized patients. Retina. 2011;31:915-23.

48. Callanan DG, Jaffe GJ, Martin DF, Pearson PA, Comstock TL. Treatment of posterior uveitis with a fluocinolone implant: threeyear clinical trial results. Arch Ophthalmol. 2008;126:1191-201.

49. No authors listed. Fluocinolone acetonide ophthalmic - Bausch \& Lomb: fluocinolone acetonide envision TD implant. Drugs R D. 2005;6:116-9.

50. Montero JA, Ruiz-Moreno JM. Intravitreal inserts of steroids to treat diabetic macular edema. Curr Diabetes Rev. 2009;5:26-32.

51. - Pearson PA, Comstock TL, Ip M, et al. Fluocinolone acetonide intravitreal implant for diabetic macular edema: a 3-year multicenter, randomized, controlled clinical trial. Ophthalmology. 2011;118:1580-7. Randomized clinical trial of fluocinolone insert.

52. Schwartz SG, Flynn HW Jr. Fluocinolone acetonide implantable device for diabetic retinopathy. Curr Pharm Biotechnol. 2011;12: 347-51.

53. Campochiaro PA, Brown DM, Pearson A, et al. Long-term benefit of sustained-delivery fluocinolone acetonide vitreous inserts for diabetic macular edema. Ophthalmology. 2011;118:626-35. 